\title{
Partial loss of migratory behaviour by Torresian Imperial- Pigeons Ducula spilorrhoa in Darwin, Northern Territory
}

\author{
Richard A. Noske ${ }^{1,2 *}$ and Amanda Lilleyman' \\ 1'Research Institute for the Environment and Livelihoods, Charles Darwin University, Darwin NT 0909, \\ Australia \\ 2Environmental Futures Research Institute, Griffith University, Nathan QLD 4111, Australia \\ *Corresponding author. Email: rnoske@tpg.com.au
}

\begin{abstract}
The Northern Territory population of the Torresian Imperial-Pigeon Ducula spilorrhoa was once considered to be completely migratory, departing for New Guinea in February and returning to breed in August. However, reporting rates from Darwin suggest that since at least the early 1990s a substantial proportion of birds 'over-winter' in the region. We monitored an evening roost-site each month from May 2011 to August 2014, counting birds in 5-minute intervals as they arrived. Mean numbers were highest during the late wet-early dry season transition months (March through May) and lowest during the late dry-early wet season transition period (September through November), although the maximum number (1325 birds) was counted in June 2011, following the wettest wet season on record. These observations confirm that many Torresian Imperial-Pigeons do not migrate to New Guinea after the breeding season, but it is not yet known if any individual birds are long-term residents. It is possible that residency in the early dry season has evolved because of year-round availability of food resources in the urban environment but we were unable to test this hypothesis.
\end{abstract}

\section{Introduction}

One of the few bird species that breed in Australia and annually migrate to New Guinea for the winter months, the Torresian Imperial-Pigeon Ducula spilorrhoa occurs in three disjunct populations across northern Australia: north-eastern Queensland, the Top End of the Northern Territory, and the Kimberley district of Western Australia (Higgins \& Davies 1996). The largest population, with counts suggesting at least 800000 birds (Thorsborne et al. 1988; Brothers \& Bone 2012), breeds in north-eastern Queensland, and is considered fully migratory. In contrast, the relatively small population of the Kimberley district is known to be resident (Storr 1980; Johnstone 1981; King 1990). The Top End population was historically considered strictly migratory, with most birds arriving in late August, and leaving by mid February, although occasional birds were recorded from March to July (Rix 1970; Crawford 1972; Frith \& Hitchcock 1974; Thompson 1978; Frith 1982).

In Darwin, Northern Territory, the species was described as late as the mid 1980s as being largely absent from April to August, albeit with 'odd birds' being found throughout the year (Thompson \& Goodfellow 1987). It was not recorded in April and May 1986 in an area of $20 \times 20 \mathrm{~km}$, centred on the Howard's and Shoal Bay Peninsulas $\sim 25 \mathrm{~km}$ east of Darwin (Woinarski et al. 1988). Before the present study, however, the only monitoring of the species in Darwin was conducted by Healey (1992) in the northern suburb of Millner, where bird censuses almost daily from 1988 through 1991 revealed small numbers (1-10) in all months except June and July. During the following year (1992), however, up to ten birds were observed through June and early July (C. Healey unpubl. data), possibly indicating a sudden increase in the number of individuals over-wintering in Darwin. Using 1385 records from a wide range of sources covering the period from 1980 to 2013, McCrie \& Noske (2015) showed that there was a distinct reduction in reporting rates in the Darwin region from March through July, which corresponds with the above migration schedule. Analyses of these records, however, show that the percentage of records pertaining to these 5 months has changed little over the four decades, ranging from $20 \%$ to $27 \%$ (R. Noske unpubl. data).

The Torresian Imperial-Pigeon has adapted well to the urban environment of Darwin, and pairs commonly nest in roadside trees and suburban gardens (McCrie \& Noske 2015). The local breeding season is mainly from August to January (Frith 1982), though opportunistic records of nesting from 1990 to 2014 suggest that over two-thirds of clutches were laid from September through November (RN unpubl. data). Observations of fledglings in late August 2005 and early September 2006 in the northern suburbs (RN unpubl. data), however, suggested that eggs are occasionally laid as early as June or July, based on a combined incubation and nestling period of 7 weeks (Higgins \& Davies 1996). This, in turn, indicates that by 2005 some adults had become resident.

A radio-tracking study conducted just outside Darwin provides strong evidence that at least some Torresian Imperial-Pigeons from the region migrate to New Guinea. One radio-tagged individual left Black Jungle, $\sim 40 \mathrm{~km}$ east of Darwin city, on 21 March 1996 and travelled $220 \mathrm{~km}$, including one flight of $80 \mathrm{~km}$, to Copeland Island, off Cobourg Peninsula, where its radio-transmitter was recovered 6 days later (Price 2006). Its trajectory suggested that it was heading for Dolak Island, adjacent to south-eastern Papua (Irian Jaya), involving a flight of another $630 \mathrm{~km}$ or, if it continued in a more northerly direction, the Aru Islands, $500 \mathrm{~km}$ away.

In order to clarify the extent of over-wintering behaviour, of Torresian Imperial-Pigeons in the Darwin region, a survey was conducted on the weekend of 26-27 June 2010. Ten suburbs and four rural areas were sampled by ten volunteers, but only small numbers (1-4 birds) were found in each of the suburbs, and none in the rural areas (RN unpubl. data). Following an observation of small flocks flying towards Darwin in the evening (S. Popple pers. 
comm.), a roost-site was found among mangroves near the city centre on 26 June, and, on the following evening, no fewer than 333 birds were counted as they arrived at the roost (A. Keates pers. obs.). This discovery prompted monthly monitoring of birds at the roost in order to clarify the status of the species in the dry season in this region.

\section{Study area and methods}

Darwin is located in the wet-dry (monsoon) tropics of northern Australia, where temperatures are relatively uniform year-round, but there is a very distinct wet season from November to April, when $90 \%$ of the rain falls (Taylor \& Tulloch 1985). The dry season comprises the months of May through October. Day length varies by only 50 minutes over the course of the year (Geoscience Australia 2015). The roost-site was located near the Dinah Beach boat-ramp (12²6'32"S, $\left.130^{\circ} 51^{\prime} 17^{\prime \prime} E\right)$, close to the mouth of Sadgroves Creek and $\sim 2.5 \mathrm{~km}$ from Darwin's city centre. Torresian Imperial-Pigeons were counted three times per month from May to August 2011, but from September 2011 to August 2014 counts took place once a month, mostly in the third or fourth week to ensure that counts were evenly spaced. Counting was initially conducted from a high vantage point $(21 \mathrm{~m}$ above sealevel) in the suburb of Bayview Haven, which overlooks the patch of mangroves that includes the roost-site, but from September 2011, counts were conducted from a boatramp, $\sim 600 \mathrm{~m}$ from the roost-site, from where birds flying in from all directions could be seen better.

On each evening sampled, Torresian Imperial-Pigeons were counted in 5-minute intervals as they arrived at the roost; counting continued until it was dark or no birds were added for five consecutive minutes. From these data, the total number of birds and the duration over which birds arrived were calculated. On several evenings some or all of the birds left the site to roost elsewhere; in such cases, the maximum number present at any one time was used as we were primarily interested in numbers of birds rather than roosting behaviour. The median time of arrival was calculated for each night, and compared with the time of sunset according to online data (Geoscience Australia 2015).

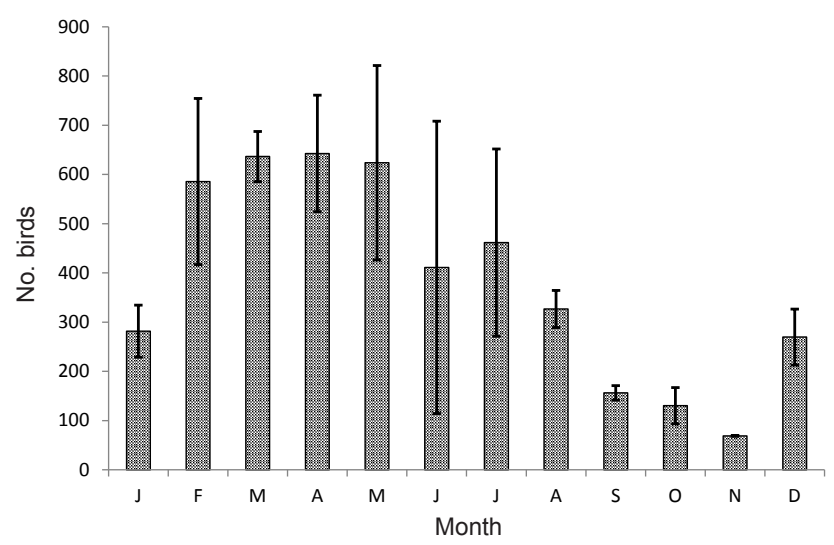

Figure 1. Mean monthly counts of Torresian ImperialPigeons from 2011 to 2014 at Dinah Beach roost-site in Darwin, Northern Territory. Vertical bars show one standard error above and below the mean.
Although counts took place on three evenings in each of the first 4 months of the study period (May to August 2011), we used only the count on the date closest to the middle of the month for statistical analysis, since counts after this period were generally performed in the third or fourth week. Monthly counts were averaged over three (SeptemberApril) or four (May-August) years to derive single means for each month. Seasonal comparisons were made using the unequal variance $t$-test, which provides more reliable results than the Mann-Whitney $U$-test when variances are unequal (Ruxton 2006). Counts for the months in which (1) the species was historically 'largely absent' (AprilAugust) according to Thompson \& Goodfellow (1987) and (2) long-term reporting rates were low (March-July: McCrie \& Noske 2015) were compared with those in the remaining months. Spearman's Rank Correlation test was used to investigate the relationship between mean group size and mean counts across all years, and chi-square tests were used to investigate seasonal variation in the size of groups arriving at the roost.

\section{Results}

The number of Torresian Imperial-Pigeons at the roost varied from 30 to 1325 birds over the 47 nights sampled, with an average of 390 birds. Mean monthly counts were generally highest during the late wet-early dry season transition months (March through May) and lowest during the late dry-early wet season transition period (September through November) (Figure 1). There was no significant difference between counts from April to August, when the species was historically largely absent and the remaining months $(t=-1.19, d f=4, P>0.1)$ or between counts from March to July, when long-term reporting rates were lowest, and August to February $(t=-2.13, d f=3, P>0.1)$. Mean annual counts were highest in 2011 (523 birds; $n=8$ ) and lowest in 2013 (292 birds; $n=12$ ). Counts in 2011 show that the number of pigeons exceeded 1000 for 2 months from mid May to mid July (Figure 2), after which it dropped sharply to the low in October-November. In the following 3 years, numbers peaked earlier but never reached 1000 , and the drop began 1-2 months earlier, in May or June. In all three wet seasons sampled, numbers increased between November and December by a factor of 2.3-4.8.

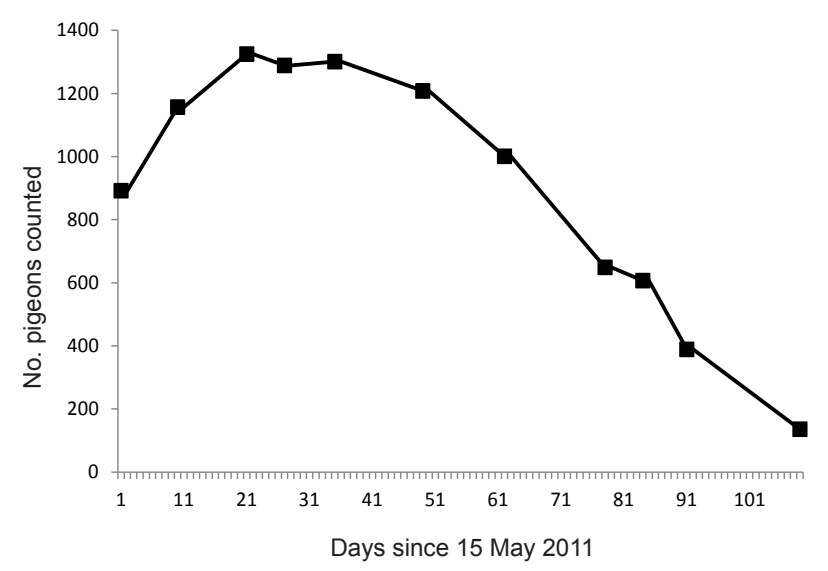

Figure 2. Number of Torresian Imperial-Pigeons counted from 15 May to 1 September 2011 at the Dinah Beach roostsite, Darwin, Northern Territory. 
Torresian Imperial-Pigeons arrived singly or in groups of up to 32 birds, with an overall mean group size of 2.4. Mean group size was highest in April 2014 (5.1 birds), and the next four highest means were in April $(2013,2012)$ or May (2012, 2014). There was a highly significant correlation between mean monthly group size and mean monthly counts across all years (Spearman's Rank Coefficient = $0.900, d f=10, P<0.01$ ). Groups of three or more birds were significantly more frequent during the months of low reporting rates of the species (March-July vs AugustFebruary; $X^{2}=132.7, d f=4, P<0.001$ ), as well as months when the species was historically largely absent (AprilAugust vs September-March; $X^{2}=119.5, d f=4, P<0.001$ : Figure 3).

The time of sunset varied by only 50 minutes over the year, the earliest sunset being in May and June (1829 h), and latest in January (1919 h). Torresian Imperial-Pigeons started arriving at the roost up to $\sim 2$ hours (124 min.) before sunset, but this varied seasonally. Arrival started significantly earlier in the wet than in the dry season (means 89.3 and $71.6 \mathrm{~min}$. before sunset, respectively; $t=5.55 ; d f=3 ; P=0.012$ ) (Figure 4). Similarly, the duration over which birds arrived was significantly longer in the wet than in the dry season (means 93.1 and $73.0 \mathrm{~min}$. before sunset, respectively; $t=4.22 ; d f=4 ; P=0.013$ ).

Torresian Imperial-Pigeons that arrived at the roost remained there until after sunset except on six nights when some or all of them left the site during the 15 minutes before sunset, flying eastwards towards Charles Darwin National Park or south-eastwards towards East Arm. These six nights were all in the dry season, and the maximum number of birds that had arrived at the site varied from 88 to 408 . The dates and percentage of birds that departed before sunset were as follows: 16 June 2012 (15\%), 29 July 2012 ( 60\%), 20 May and 15 July 2013 (100\%), 11 August 2013 (92\%) and 11 June 2014 (40\%). Departing birds left as individuals or in groups of up to 30, except on 11 August 2013, when 290 birds departed almost instantaneously at $1845 \mathrm{~h}$, and 43 left 5 minutes later, apparently because of disturbance caused by a goshawk Accipiter sp., which was seen flying from the roost-site to the boat-ramp.

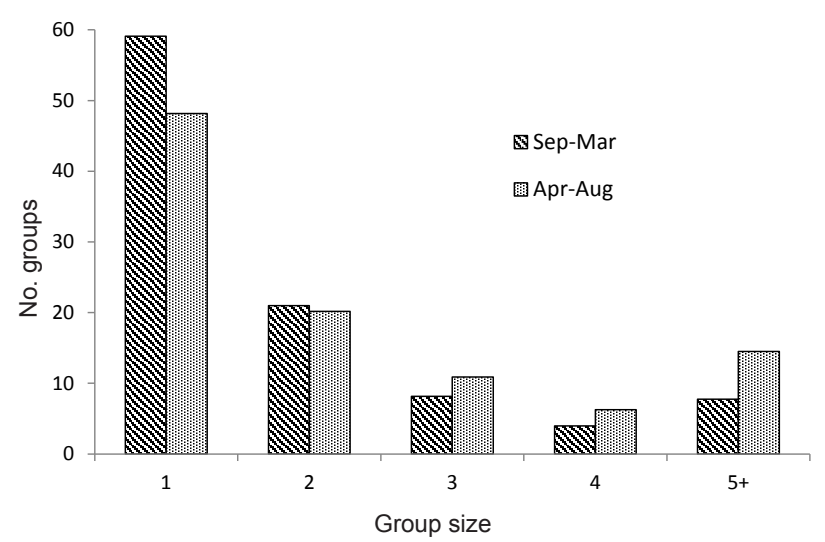

Figure 3. Frequency of group sizes of Torresian ImperialPigeons arriving at the Dinah Beach roost-site, Darwin, Northern Territory.

\section{Discussion}

Although the Top End population of the Torresian ImperialPigeon was formerly considered to be strictly migratory, as is the population in north-eastern Queensland, this study demonstrates that the species occurs throughout the year in the Darwin region, with a substantial number over-wintering. Up to 1325 birds (mean 485) were present at the Dinah Beach roost-site during the 5 months (April through August) when the species was reported to be largely absent from Darwin until the mid or late 1980s (Thompson \& Goodfellow 1987). The roost-site appeared to be occupied continuously for at least 40 months (from May 2011 to August 2014, when the study finished), except in May and July 2013, when all birds (88 and 118, respectively) that had arrived at the site during the first 40-45 minutes of observation departed before nightfall. Although the departure of 333 birds from the site on 11 August 2013 appeared to be related to disturbance by a potential aerial predator, the reason for the abandonment of the roost-site in May and July is unknown. Clearly, however, alternative roost-sites were used on these nights, possibly within the extensive tracts of mangroves to the south-east of the study site.

The counts show a consistent, albeit variable, drop in numbers of Torresian Imperial-Pigeons each year during August, coinciding with the start of the main breeding season in Darwin. Extrapolation of laying dates from 74 breeding records in Darwin between 1990 and 2014 suggest that clutches (always one egg) are laid equally frequently in the 3 months from September through November, together comprising $69 \%$ of nests observed (RN unpubl. data). The August decline in numbers of birds at the roost also coincides with an increase in the frequency of sightings of the species in Darwin (McCrie \& Noske 2015), presumably because of, in part at least, the arrival of migratory individuals from outside Australia. However, these individuals are likely to begin breeding immediately after their arrival (Frith 1982), along with any birds that may be resident in Darwin. In north Queensland, males and females of this species take turns at incubating on alternate days, the changeover taking place in the late

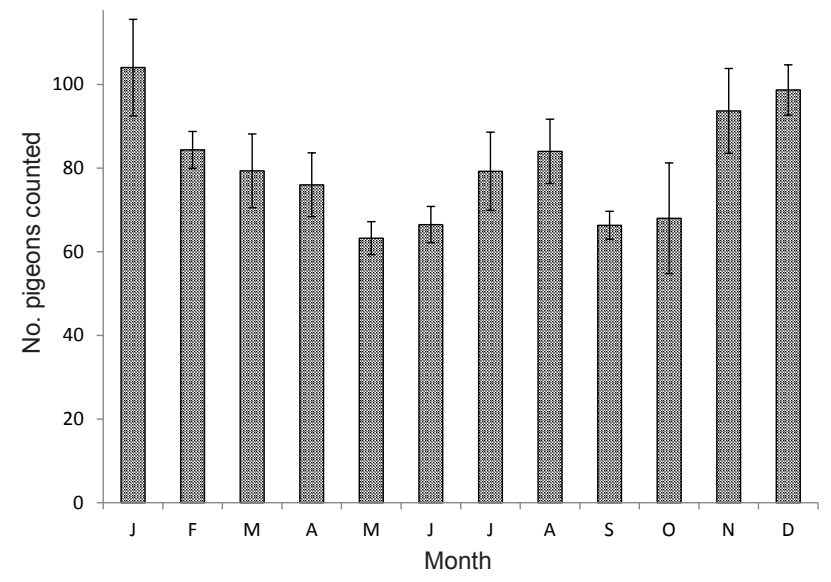

Figure 4. Mean monthly variation in start of arrival of Torresian Imperial-Pigeons at the Dinah Beach roost-site, Darwin, Northern Territory, in relation to time of sunset from May 2011 through August 2014. Vertical bars show one standard error above and below the mean. 
afternoon (Crome 1975). It is possible that one member of each nesting pair roosts communally while its mate is incubating. This might explain why numbers at the Dinah Beach roost-site declined by $51-65 \%$ between August and September in each of the complete dry seasons sampled.

The counts also show that the number of Torresian Imperial-Pigeons using the roost in mid November was remarkably consistent in each of the three sampled wet seasons (68-71 birds), but that number increased twoto almost five-fold before mid December, coinciding with the decline in laying. Given that the egg takes 4 weeks to hatch, and the chick another 4 weeks to fledge (Higgins \& Davies 1996), most fledglings may be expected to appear from November through January (see also Healey 1992). It therefore seems plausible that the increase in number of Pigeons at the Dinah Beach roost-site between November and December was due to the arrival or return of pairs with young. Thorsborne et al. (1988) suggested that juvenile recruitment is a probable cause of annual population peaks in the north-eastern Queensland population. The species is multi-brooded, at least in north-eastern Queensland, with pairs rearing up to three chicks in one season (Crome 1975). On the other hand, the dramatic increase in number of birds at the Dinah Beach roost-site in February seems too large to be solely attributable to the addition of juveniles from late broods, suggesting that the site may attract birds from areas surrounding, as well as within, Darwin.

In contrast with counts of Torresian Imperial-Pigeons during much of the wet season, counts during the first 3 months of the dry season (May-July; early dry season, hereafter abbreviated EDS) were markedly variable (Figure 1). Much of this variability was because of high inter-annual variation, with the EDS median count of 2011 being almost nine times that of 2013 (1001 and 113 birds, respectively). As these months include the period when migratory individuals are expected to be absent, it seems likely that the unusually high numbers in 2011 were related to extreme weather associated with Tropical Cyclone Carlos in February 2011, which resulted in the wettest month in Darwin on record $(1110 \mathrm{~mm}$ rain: Bureau of Meteorology 2015). Such exceptionally heavy rainfall and strong winds may have directly interfered with the departure of migratory birds, or caused damage to fruit, thus reducing the food supply available to birds before departure. Indeed, there may be a relationship between wet-season rainfall and numbers of Torresian ImperialPigeons using the roost during the following dry season, though we have too few data to test its strength. Total rainfall for the wet season (November-April) preceding the high EDS counts of 2011 was $2761 \mathrm{~mm}$, which was twice that of the wet-season rainfall preceding the lowest EDS counts (2013), and 1.6 times higher than the rainfalls for the two wet seasons that preceded the 2012 and 2014 EDS counts. Chambers et al. (2014) showed that for some Australian species, precipitation (especially number of rainy days) was a more important driver of movements than temperature.

The Torresian Imperial-Pigeon in the Darwin region may be described best as a partial migrant (Gauthreaux 1982; Chan 2001), given that some birds are migratory (Price 2006), whereas others are clearly non-migratory. When partial migration is fixed at the individual level it may be termed 'obligate', while individuals that change their migratory tendency over their lifetime are termed 'facultative' (Terrill \& Able 1988; Palacín et al. 2011). In short-lived small passerines, experimental studies have shown that differences among populations in migratory behaviour are mostly genetically determined (Berthold \& Pulido 1994; Pulido \& Berthold 2010), though other studies suggest that environmental factors, or individual condition and experience, may also be important (Pulido et al. 1996; van Noordwijk et al. 2006; Ogonowski \& Conway 2009). By contrast, migratory behaviour seems to be learned in large non-passerines with extended parental care (e.g. swans, geese and cranes), as the young migrate with their parents; the offspring of non-migrating adults do not migrate. In the long-lived Great Bustard Otis tarda, up to $30 \%$ of females changed their migratory pattern between consecutive years, tending to remain sedentary in years when they had dependent young to attend (Palacín et al. 2011). The migratory tendency of Torresian Imperial-

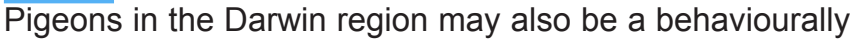
flexible, condition-dependent trait.

One possible explanation for 'over-wintering' behaviour or long-term residency of Torresian Imperial-Pigeons in Darwin is probably that some food resources are available throughout the dry season in the urban environment (McCrie \& Noske 2015). The species is an obligate frugivore, and is known to eat the fruit of at least 30 plant species in Top End rainforests (Price 2006). Urban pigeon populations appear to be heavily dependent on the fruit of several cultivated native plant species, including Carpentaria Palm Carpentaria acuminata, Umbrella Tree Schefflera actinophylla and Weeping Fig Ficus benjamina, all of which are widely planted in Darwin suburbs. Over half of the seeds collected below a day-time roost in Millner during September 1991 came from Carpentaria Palms, and a quarter from Maranthes corymbosa (Healey 1992). In wet monsoon rainforests $\sim 40 \mathrm{~km}$ east of Darwin, Bach (2002) found that the peak production of fruit occurred during the early-to-middle wet season, whereas in dry monsoon rainforests on the coast, this peak occurred 3-4 months later, during the late wet-early dry season. Paradoxically, the latter period is when migratory Torresian Imperial-Pigeons leave for New Guinea. We did not collect phenological data on food-plant species in Darwin suburbs, but we have opportunistic records of pigeons and other frugivorous birds feeding on the fruit of Weeping Figs in May and June in three separate years (RN unpubl. data).

Food availability may also explain the observed seasonal variation in group size and duration of arrival of the Torresian Imperial-Pigeons at the roost-site. During the mid-to-late wet season, the fruit of rainforest trees is widely available (Bach 2002), so many birds do not need to travel far to locate food, and those individuals that can quickly satisfy their energy requirements are able to move to the roost much earlier than others. As this period also coincides with the late breeding season, many groups will consist of pairs with or without their single offspring. During the early dry season, on the other hand, fruiting rainforest trees are relatively scarce and patchy, forcing overwintering pigeons to aggregate into larger groups and fly further to find food sources, the majority of birds returning to the roost at a similar time. Radio-tracking shows that local Torresian Imperial-Pigeons travel up to $14 \mathrm{~km}$ (mean $4.5 \mathrm{~km}$ ) between rainforest patches every 3 days (Price 2006). Further research on the local population, involving trapping, marking and satellite-tracking, would be useful 
to determine whether the majority of over-wintering individuals are first-year birds (as is the case with migratory shorebirds) or whether they are residents over multiple years. Combined with the above methods, blood samples might be used to ascertain if there is a genetic component to non-migratory behaviour.

\section{Acknowledgements}

We are indebted to Gavin and Meg O'Brien, who organised and participated in all counts from April 2013 to August 2014, and to Arthur and Sheryl Keates, who did the same during June-July 2010 and from May to August 2011. AL was assisted by Jan Allen, Bret Stewart, Tiffanie Pearse and Cameron Dean during counts on several evenings. Counters during the pilot project were Steve Popple, Heather Ryan, Kim Low Choy, Marc Gardner, Mat Gilfedder, Mike Jarvis, Don Franklin and Peter Kyne. Finally, we are grateful to Don Franklin and two anonymous referees for their constructive criticism of previous versions of this manuscript.

\section{References}

Bach, C.S. (2002). Phenological patterns in monsoon rainforests in the Northern Territory, Australia. Austral Ecology 27, 477-489.

Berthold, P. \& Pulido, F. (1994). Heritability of migratory activity in a natural bird population. Proceedings of the Royal Society $B$ : Biological Sciences 257, 311-315.

Brothers, N. \& Bone, C. (2012). Torresian Imperial Pigeon Ducula spilorrhoa monitoring, population trends and species suitability as an indicator of environmental changes. Corella 36, 69-75.

Bureau of Meteorology (2015). Tropical cyclones in the Northern Territory. Available online: http://www.bom.gov.au/cyclone/ about/northern.shtml\#history (retrieved 15 November 2015).

Chambers, L.E., Beaumont, L.J. \& Hudson, I.L. (2014). Continental scale analysis of bird migration timing: Influences of climate and life history traits - a generalized mixture model clustering and discriminant approach. International Journal of Biometeorology 58, 1147-1162.

Chan, K. (2001). Partial migration in Australian landbirds: A review. Emu 101, 281-292.

Crawford, D.N. (1972). Birds of the Darwin area; with some records from other parts of the Northern Territory. Emu 72, 131-147.

Crome, H.J. (1975). Breeding, feeding and status of the Torres Strait Pigeon at Low Isles, north-eastern Queensland. Emu 75, 189-198.

Frith, H.J. (1982). Pigeons and Doves of Australia. Rigby, Adelaide.

Frith, H.J. \& Hitchcock, W.B. (1974). Birds. In: Frith, H.J. \& Calaby, J.H. (Eds). Fauna Survey of the Port Essington District, Cobourg Peninsula, Northern Territory of Australia, pp. 109-178. CSIRO Division of Wildlife Research Technical Paper No. 28. CSIRO, Canberra.

Gauthreaux, J.S.A. (1982). The ecology and evolution of avian migration systems. In: Farner, D.S., King, J.R. \& Parkes, K.C. (Eds). Avian Biology, pp. 93-163. Academic Press, New York.

Geoscience Australia (2015). Sunrise, sunset and twilight times. Available online: www.ga.gov.au/bin/geodesy/run/sunrisenset (retrieved 17 January 2015).

Healey, C. (1992). Abundance, diet and roosting defecations of the Torresian Imperial-Pigeon (Ducula spilorrhoa) in Darwin. Corella 16, 107-110.
Higgins, P.J. \& Davies, S.J.J.F. (Eds) (1996). Handbook of Australian, New Zealand \& Antarctic Birds, Volume 3: Snipe to Pigeons. Oxford University Press, Melbourne.

Johnstone, R. (1981). Notes on the distribution, ecology and taxonomy of the Red-crowned Pigeon (Ptilinopus regina) and Torres Strait Pigeon (Ducula bicolor) in Western Australia. Records of the Western Australian Museum 9, 7-22.

King, B. (1990). Distribution and status of the Torresian Imperial Pigeon Ducula spilorrhoa in north-eastern Queensland: Cooktown to Cape York. Emu 90, 248-253.

McCrie, N. \& Noske, R. (2015). Birds of the Darwin Region. CSIRO Publishing, Melbourne.

Ogonowski, M.S. \& Conway, C.J. (2009). Migratory decisions in birds: Extent of genetic versus environmental control. Oecologia 161, 199-207.

Palacín, C., Alonso, J.C., Alonso, J.A., Magaña, M. \& Martín, C.A. (2011). Cultural transmission and flexibility of partial migration patterns in a long-lived bird, the great bustard Otis tarda. Journal of Avian Biology 42, 301-308.

Price, O.F. (2006). Movements of frugivorous birds among fragmented rainforests in the Northern Territory, Australia. Wildlife Research 33, 521-528.

Pulido, F. \& Berthold, P. (2010). Current selection for lower migratory activity will drive the evolution of residency in a migratory bird population. Proceedings of the National Academy of Sciences of USA 107, 7341-7346.

Pulido, F., Berthold, P. \& van Noordwijk, A.J. (1996). Frequency of migrants and migratory activity are genetically correlated in a bird population: Evolutionary implications. Proceedings of National Academy of Sciences of USA 93, 14642-14647.

Rix, C.E. (1970). Birds of the Northern Territory. South Australian Ornithologist 25, 147-191.

Ruxton, G.D. (2006). The unequal variance t-test is an underused alternative to Student's t-test and the Mann-Whitney $\mathrm{U}$ test. Behavioural Ecology 17, 688-690.

Storr, G.M. (1980). Birds of the Kimberley Division, Western Australia. Special Publication number 11. Western Australian Museum, Perth.

Taylor, J.A. \& Tulloch, D. (1985). Rainfall in the wet-dry tropics: Extreme events at Darwin and similarities between years during period, 1870-1983 inclusive. Australian Journal of Ecology 10, 281-295.

Terrill, S.B. \& Able, K.P. (1988). Bird migration terminology. Auk 105, 205-206.

Thompson, H.A.F. (1978). Common birds of the Darwin suburbs. Northern Territory Naturalist 1, 7-12.

Thompson, H.A.F. \& Goodfellow, D. (1987). Common Birds of the Darwin Area. Sandpiper Productions, Darwin.

Thorsborne, A., Thorsborne, M. \& Winter, J. (1988). Population changes of the Torresian Imperial-pigeon (Ducula spilorrhoa) over twenty-one years on North Brook Island, North Queensland. Emu 88, 1-8.

van Noordwijk, A.J., Pulido, F., Helm, B., Coppack, T., Delingat, J., Dingle, H., Hedenström, A., van der Jeugd, H., Marchetti, C., Nilsson, A. \& Pérez-Tris, J. (2006). A framework for the study of genetic variation in migratory behaviour. Journal of Ornithology 147, 221-233.

Woinarski, J.C.Z., Tidemann, S.C. \& Kerrin, S. (1988). Birds in a tropical mosaic: The distribution of bird species in relation to vegetation patterns. Australian Wildlife Research 15, 171-196.

Received 27 August 2015, accepted 7 December 2015, published online 20 October 2016 